\title{
Von Willebrand factor and esophageal varices in children with chronic liver diseases
}

\author{
Mohamed Abdel-Salam El-Guindi', Nermin Mohammed Adawy', Iman Shaban Osheba², Wafaa Masoud Khalifa', \\ Hosam Eldin Mohammed Basiouny ${ }^{1}$ \\ 'Department of Pediatric Hepatology, Gastroenterology and Nutrition, National Liver Institute, Menoufia University, Shebin El-koom, Menoufia, \\ Egypt \\ 2Department of Clinical Pathology, National Liver Institute, Menoufia University, Shebin El-koom, Menoufia, Egypt \\ ${ }^{3}$ Department of Pediatrics, Mahalet Marhom hospital, Algharbeia, Ministry of Health and Population, Egypt
}

\begin{abstract}
Aim of the study: To evaluate the role of plasma level of von Willebrand factor antigen (vWF-Ag) as a possible predictor for the presence of esophageal varices (EVs) in children with chronic liver diseases (CLDs).

Material and methods: All patients underwent upper esophagogastroduodenoscopy (EGD) and were categorized as group I (had EVs) and group II (had no EVs). The following patient data were determined: Child-Pugh score (CPS), plasma vWF-Ag, vWF-Ag/thrombocyte ratio (VITRO) score, aspartate transaminase (AST) to platelet ratio index (APRI) score, AST/alanine transaminase (ALT), platelet count/spleen diameter, grading of EVs (small, medium and large) and categorizing the stage of liver fibrosis.

Results: The analysis included 50 patients with CLD; 30 (60\%) were female. The commonest etiological diagnoses were autoimmune hepatitis (AIH) (20\%) and extra-hepatic biliary atresia (EHBA) (12\%). 26\% of cases were categorized as undiagnosed CLD. The CPS showed CPS-A 34\%, CPS-B 44\% and CPS-C 22\%. The vWF-Ag was found at a high level of $243.52 \pm 195.97$, with a highly statistically significant difference in discriminating the EVs with $74 \%$ accuracy at a cut-off value of $108.99 \mathrm{IU} / \mathrm{ml}, p<0.0001$. Also, ROC analysis was performed for discriminating large esophageal varices with $84 \%$ accuracy at a cut-off value of $475.85 \mathrm{mg} \%$. The VITRO score at a cut-off value of 1.72 could detect EVs with $70 \%$ sensitivity, $86.7 \%$ specificity, and $80 \%$ accuracy.

Conclusions: High vWF-Ag is a valuable prognostic tool for estimating the presence of EVs, and higher vWF-Ag is associated with increased grade of EVs.
\end{abstract}

Key words: chronic liver diseases, von Willebrand factors, esophageal varices.

\section{Address for correspondence}

Hosam Eldin Mohammed Basiouny, Department of Pediatric Hepatology, Gastroenterology and Nutrition, National Liver Institute, Menoufia University, 32511 Shebin El-koom, Menoufia, Egypt, e-mail: hosam_292@yahoo.com

\section{Introduction}

Cirrhosis is a pathologic condition characterized by fibrosis of the liver parenchyma and evidence of regenerative activity, resulting in portal hypertension $(\mathrm{PH})$ [1]. $\mathrm{PH}$ is the underlying pathophysiological process that leads to the formation of porto-systemic collaterals and heralds the onset of a severe complication, e.g. variceal hemorrhage. The presence of varices also indicates disease progression and worse prognosis in compensated patients. Esophageal varices (EVs) are present only in about $30 \%$ of patients with compensated and $60 \%$ with decompensated cirrhosis. Their presence usually correlates with the severity of liver disease [2].

Despite the therapeutic advances achieved in the last decades, bleeding from EVs is the most feared complication of $\mathrm{PH}$, still carrying the highest mortali- 
ty rates of any of the major causes of bleeding [3]. It is estimated that approximately $50 \%$ of pediatric patients with chronic liver disease will experience gastrointestinal bleeding [4]. Esophagogastroduodenoscopy (EGD) is considered the primary modality for detection and surveillance of EVs and to determine the risk of bleeding. The guidelines for adult and pediatric cirrhotic patients recommend universal EV screening by EGD at the time of the diagnosis of cirrhosis [5].

Von Willebrand factor is a large, multimeric and highly glycosylated protein which plays a crucial role in both primary hemostasis, by mediating platelet aggregation and adhesion to the sub-endothelium at sites of vascular lesions, as well as in blood coagulation by acting as the blood carrier of factor VIII [6]. It is released by activated endothelial cells, so it is considered as an indicator of endothelial activation and development of thrombotic vascular obliteration and the possible mechanism of $\mathrm{PH}$ [7].

The aim of this study was to evaluate the role of plasma level of von Willebrand factor antigen (vWF-Ag) as a possible predictor for the presence of EVs in children with chronic liver diseases.

\section{Material and methods}

\section{Patients' recruitment}

This study included 50 patients with chronic liver diseases (CLDs), attending the outpatient clinic and inpatient of the Pediatric Hepatology, Gastroenterology and Nutrition Department, National Liver Institute, Menoufia University, over a period from July 2016 to June 2017; 30 were female and 20 male. Their mean age \pm SD was $6.5 \pm 5.3$ years.

Signed informed consent was obtained from the parents of all the patients before enrollment in this study. The study was approved by the Research Ethics Committee of the National Liver Institute. (National Liver Institute IRB number 00128/2017).

Inclusion criteria: All patients with CLDs (the disease duration is more than 6 months) referred to the Pediatric Hepatology, Gastroenterology and Nutrition Department, undergo for the first time diagnostic EGD with no previous intervention endoscopic maneuver.

Exclusion criteria: Patients documented having EVs and on sclerotherapy, patients who received medical treatment as primary prophylaxis for esophageal variceal bleeding, patients with cardiopulmonary failure, patients with renal failure, patients who presented with active infection and well-known cases of vWF-Ag.
All the patients were subjected to full history taking and thorough clinical examination, and laboratory investigations in the form of:

1. Liver function tests: All patients had liver function tests: aspartate transaminase (AST), alanine transaminase (ALT), alkaline phosphatase (ALP), $\gamma$ glutamyl-transferase (GGT), total bilirubin (TB) direct bilirubin (DB), total proteins (TP) and albumin; these tests were carried out using an Integra 400 auto analyzer (Roche Diagnostics Corporation 9115, Hague Road, Indianapolis, USA). Prothrombin time, concentration and INR: It was done using Thrombrel-S (human thromboplastin containing calcium). Complete blood count (CBC): hemoglobin ( $\mathrm{Hb})$, red blood cells (RBCs), white blood cells (WBCs), mean platelet volume (MPV), mean corpuscular volume (MCV), mean corpuscular hemoglobin $(\mathrm{MCH})$ and mean corpuscular hemoglobin (MCHC); these tests were carried out using a Sysmex automated hematology analyzer. C-reactive protein: It was done by Sysmex Counter K-1000, Japan, catalogue number: A 5873. Blood group: It was done by column agglutination technique using glass beads.

2. Plasma level of vWF-Ag: The concentration of (vWF-Ag) in plasma samples from patients and from normal persons was evaluated using Enzyme-Linked Immunosorbent Assay for human vWF-Ag Test Kit, catalog no. (vWF-Ag Kit 034-001) GS1 (Corgenix Medical Corporation, USA).

3. Abdominal ultrasonography and Doppler: It was done by real time ultrasound and Doppler equipment with a 3.5 MHz Aloka SSD 680, Tokyo, Japan, to assess the size and echo pattern of the liver, the size of the spleen, the presence of ascites. The proper PV velocity, hepatic vein $(\mathrm{HV})$ velocity and HA resistive index were scanned proximal to the porta hepatis during suspended respiration.

4. Liver biopsy: A US guided liver biopsy was performed whenever possible, by Tru-Cut needle of a size of 14 gauge $\times 20 \mathrm{~cm}$ after sedation of patients. Biopsy specimens were fixed in formalin, embedded in paraffin and the prepared slides were stained with hematoxylin and eosin, Masson's trichrome, Orcein, and Perl's stains for routine histopathological evaluation. The liver biopsies were analyzed according to the Ishak Classification, fibrosis was classified into no fibrosis (stage 0 ), mild (stage 1), moderate (stages 2-3), and severe fibrosis or cirrhosis (stages 4-6). Then stages of fibrosis were classified as stages 1 and 2 (preserved hepatic architecture), stages 3 and 4 (partially disturbed hepatic architecture) and stages 5 and 6 (disturbed hepatic architecture) [8].

5. Upper endoscopy: Complete examination for esophagus, stomach and duodenum using an Olym- 
pus GIF-H170 device with light source CLV-U40 and processor CV-240.

6. According to the endoscopic findings, patients were classified into two groups: group I - patients who had EVs, group II - patients who had no EVs.

Grading of EVs when found was done according to the North Italian Endoscopy Club (NIEC) classification as follows [9]:

- grade I: Variceal diameter less than $2 \mathrm{~mm}$, disappear with esophageal lumen insufflation,

- grade II: Varices of similar diameter, clearly visible in the esophageal lumen,

- grade III: Varices of 3-4 mm, prominent in the esophageal lumen,

- grade IV: Variceal diameter $5 \mathrm{~mm}$ or more, tortuous,

- grade V: Red color signs.

Grades I and II were classified as small varices, grade III was classified as medium size varices while grade IV was classified as large varices.

\section{Statistical analysis}

The data collected were tabulated and analyzed by SPSS Statistics, version 21 on an IBM compatible computer [9]. Quantitative data were expressed as mean and standard deviation $(\mathrm{X} \pm \mathrm{SD})$ and analyzed by applying the Mann-Whitney $U$ test for non-normally distributed variables. The Kruskal-Wallis test was used for comparison of more than two groups of non-normally distributed variables. Qualitative data were expressed as number and percentage (no. and \%) and analyzed by applying the $\chi^{2}$ test. Spearman correlation $(r)$ was used to detect associations between quantitative vari-

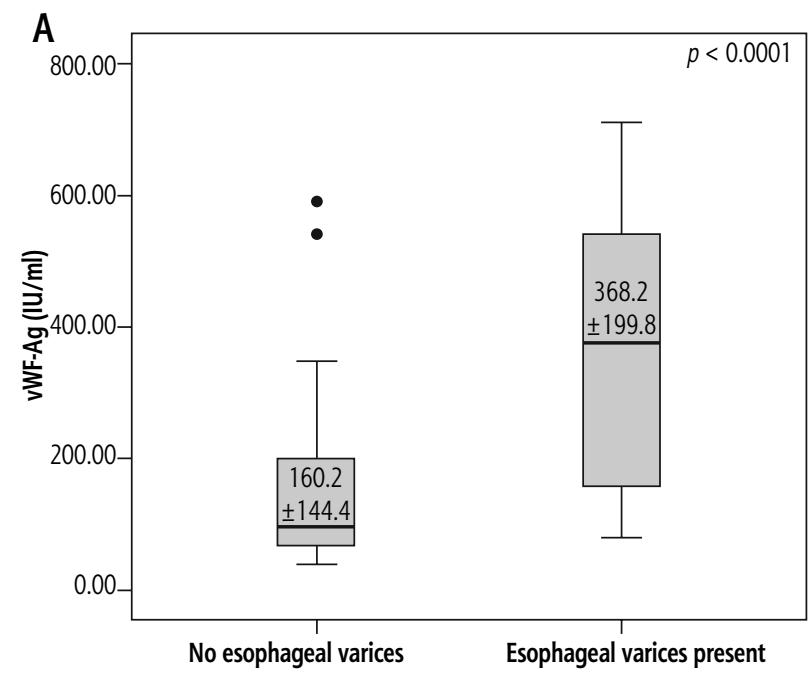

ables. All these tests were used as tests of significance at $p<0.05$.

\section{Results}

The present study included 50 children with CLDs; $30(60 \%)$ patients were female and $20(40 \%)$ were male. All patients underwent EGD for the first time. Regarding the etiology in both groups, revision of medical files of all patients revealed that $20 \%$ were diagnosed with autoimmune hepatitis (AIH) treated with prednisolone and azathioprine, 12\% extra-hepatic biliary atresia (EHBA) treated by Kasai operation, $10 \%$ Wilson disease treated with D-penicillamine, $12 \%$ congenital hepatic fibrosis treated with ursodeoxycholic acid, 8\% Caroli disease treated with ursodeoxycholic acid, $8 \%$ progressive familiar intrahepatic holestasis (PFIC) treated with ursodeoxycholic acid. Tyrosinemia treated with ursodeoxycholic acid and galactosemia treated with lactose free diet represented $2 \%$ for each, while $26 \%$ were categorized as undiagnosed CLD.

The majority of patients (78\%) were classified as Child-Pugh score (CPS)-A and CPS-B, while (22\%) were CPS-C. According to the endoscopic examination results, $40 \%$ of the studied group had EVs while $60 \%$ had no EVs.

Liver biopsy was done only for 33 because of coagulopathy and it was found that 18 patients had partially disturbed hepatic architecture while 8 patients were found to have preserved and disturbed hepatic architecture for each.

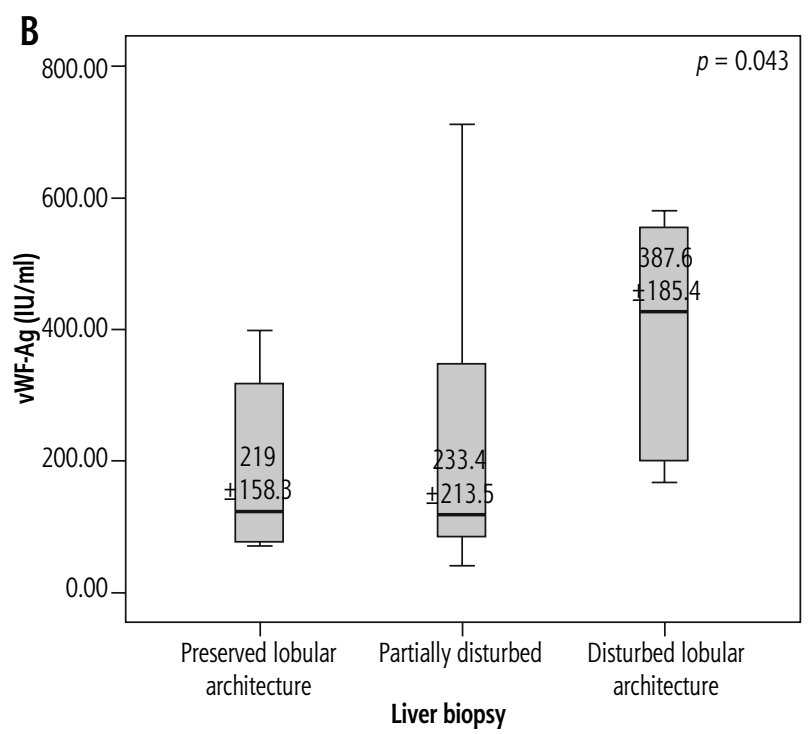

Fig. 1. A) Box and whisker graph of plasma vWF-Ag level in group I and group II. B) Box and whisker graph of plasma vWF-Ag level at different stages of liver fibrosis 
Table 1. Correlation between vWF-Ag and patients' parameters

\begin{tabular}{|c|c|c|}
\hline \multirow[t]{2}{*}{ Parameters } & \multicolumn{2}{|c|}{ vWF-Ag } \\
\hline & $t$ & $p$ \\
\hline Age (years) & 0.141 & 0.156 \\
\hline $\mathrm{TB}(\mathrm{mg} / \mathrm{dl})$ & 0.192 & 0.049 \\
\hline $\mathrm{DB}(\mathrm{mg} / \mathrm{dl})$ & 0.141 & 0.150 \\
\hline $\operatorname{TP}(g / d l)$ & -0.202 & 0.040 \\
\hline Albumin (g/dl) & -0.332 & 0.001 \\
\hline AST (U/I) & -0.014 & 0.887 \\
\hline ALT (U/l) & -0.099 & 0.311 \\
\hline $\operatorname{ALP}(\mathrm{U} / \mathrm{I})$ & -0.032 & 0.744 \\
\hline GGT (U/I) & 0.034 & 0.725 \\
\hline Urea (mg/dl) & 0.057 & 0.563 \\
\hline Creatinine (mg/dl) & -0.022 & 0.821 \\
\hline Hemoglobin (g/dl) & -0.103 & 0.295 \\
\hline $\operatorname{RBC}\left(10^{6} / \mu \mathrm{l}\right)$ & 0.039 & 0.696 \\
\hline $\mathrm{WBC}\left(10^{3} / \mu \mathrm{l}\right)$ & -0.176 & 0.072 \\
\hline Platelet $\left(10^{3} / \mu \mathrm{l}\right)$ & -0.196 & 0.046 \\
\hline MPV (fl) & 0.082 & 0.418 \\
\hline MCV (fl) & 0.034 & 0.732 \\
\hline $\mathrm{MCH}(\mathrm{pg})$ & 0.066 & 0.498 \\
\hline $\mathrm{MCHC}(\mathrm{g} / \mathrm{dl})$ & 0.119 & 0.234 \\
\hline CRP (mg/l) & -0.043 & 0.668 \\
\hline PT (s) & 0.124 & 0.206 \\
\hline PC (\%) & -0.085 & 0.384 \\
\hline INR & 0.144 & 0.143 \\
\hline Liver size & -0.030 & 0.768 \\
\hline Portal vein & -0.051 & 0.724 \\
\hline Spleen size & 0.144 & 0.147 \\
\hline PV flow $(\mathrm{cm} / \mathrm{s})$ & -0.334 & 0.027 \\
\hline HVs flow $(\mathrm{cm} / \mathrm{s})$ & -0.046 & 0.764 \\
\hline HA Resistive Index & 0.216 & 0.154 \\
\hline
\end{tabular}

ALT - alanine aminotransferase, ALP - alkaline phosphatase, AST - aspartate aminotransferase, GGT - $\gamma$ glutamyl-transferase, DB - direct bilirubin, $H b$ - hemoglobin, HAs - hepatic arteries, HVs - hepatic veins, MPV - mean platelet volume, MCV - mean corpuscular volume, $M C H$ - mean corpuscular hemoglobin, $M C H C$ - mean corpuscular hemoglobin, $P V$ - portal vein, RBCS - red blood cells, TB - total bilirubin, TP - total proteins, WBCS - white blood cells

The mean \pm SD of plasma vWF-Ag level was higher in group I $(368.2 \pm 199.8 \mathrm{IU} / \mathrm{ml})$ than group II $(160.4 \pm 144.4 \mathrm{IU} / \mathrm{ml})$ with a highly statistically significant difference $(p<0.0001)$. The mean \pm SD of plasma vWF-Ag increased with increased degree of fibrosis, with a statistically significant difference $(p<0.05)$ (Fig. 1). Also, the mean \pm SD of plasma vWF-Ag level was found to be higher in patients with a non-O blood group than that in patients with a $\mathrm{O}$ blood group, with a statistically significant difference $(p<0.05)$.
Table 2. Comparison of AST/ALT, APRI score, platelet count/spleen diameter and VITRO in patients in group I and group II

\begin{tabular}{lccc}
\hline Parameters & \multicolumn{2}{c}{ EV } & P-value \\
\cline { 2 - 3 } & $\begin{array}{c}\text { Group I } \\
(\boldsymbol{n}=\mathbf{2 0 )}\end{array}$ & $\begin{array}{c}\text { Group II } \\
(\boldsymbol{n}=\mathbf{3 0 )}\end{array}$ & \\
\hline AST/ALT & $1.88 \pm 0.99$ & $2.08 \pm 1.51$ & 0.729 \\
\hline APRI score & $3.91 \pm 3.67$ & $4.47 \pm 7.59$ & 0.482 \\
\hline $\begin{array}{l}\text { Platelet count/spleen } \\
\text { diameter }\end{array}$ & $2.14 \pm 4.25$ & $2.67 \pm 3.14$ & 0.118 \\
\hline VITRO score & $3.91 \pm 3.63$ & $1.03 \pm 1.02$ & 0.0001 \\
\hline
\end{tabular}

Table 3. Plasma vWF-Ag level at different upper endoscopic findings in group I patients

\begin{tabular}{lcccc}
\hline Parameters & & $\mathbf{n = 2 0}$ & v WF-Ag & P-value \\
\cline { 3 - 4 } & & \multicolumn{1}{c}{ Mean \pm SD } & \\
\hline $\begin{array}{l}\text { Grades of } \\
\text { esophageal } \\
\text { varices }\end{array}$ & $\begin{array}{c}\text { Grade I and II } \\
\text { (small) }\end{array}$ & 10 & $250.78 \pm 158.53$ & 0.025 \\
\cline { 2 - 4 } & $\begin{array}{c}\text { Grade III } \\
\text { (medium) }\end{array}$ & 8 & $471.44 \pm 187.44$ & \\
\cline { 2 - 4 } & Grade IV (large) & 2 & $542.33 \pm 52.95$ & \\
\hline
\end{tabular}

Our results showed that plasma vWF-Ag had a negative statistically significant correlation with total protein, serum albumin, platelet count and PV flow, but it had a positive statistically significant correlation with total bilirubin level $(p<0.05)$ (Table 1$)$.

It was found that VITRO score was higher in group I than group II, with a highly statistically significant difference $(p<0.0001)$, while AST/ALT ratio, AST to platelet ratio index (APRI) score and platelet count/ spleen diameter score were evaluated between the two groups regarding these parameters, with no statistically significant difference $(p \geq 0.05)$ (Table 2$)$.

On correlating the grades of the EVs with the plasma level of vWF-Ag, it was found that the mean \pm SD of plasma vWF-Ag level increased with grade of the EVs, with a statistically significant difference $(p<0.05)$ (Table 3 and Fig. 2).

Plasma vWF-Ag level at a cut-off value of 108.99 $\mathrm{IU} / \mathrm{ml}$ could discriminate patients having EVs from patients without EVs with $90 \%$ sensitivity, $63.3 \%$ specificity and accuracy of $74 \%$. In this study, vWF-Ag level at a cut-off value of $475.85 \%$ could discriminate patients with large varices from patients having small or medium sized varices, with $100 \%$ sensitivity and $83.33 \%$ specificity (Fig. 3 ).

The VITRO score at a cut-off value of 1.72 could discriminate patients having EVs from patients without EVs with $70 \%$ sensitivity, $86.67 \%$ specificity and accuracy of $80 \%$ (Fig. 4). 

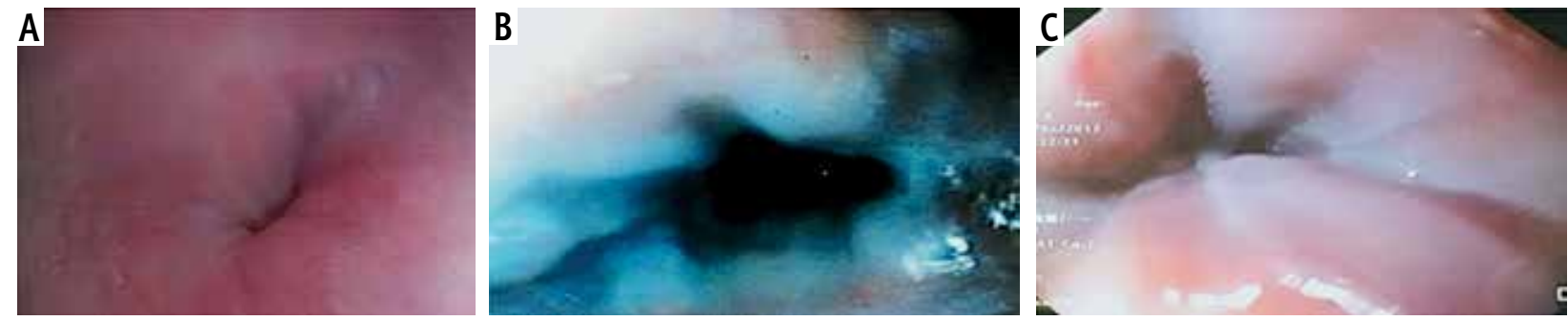

Fig. 2. A) No esophageal varices in 13-year-old female patient with autoimmune hepatitis; her plasma vWF-Ag level was $51.93 \mathrm{IU} / \mathrm{ml}$. B) IV cords small esophageal varices in 2-year-old male patient with congenital hepatic fibrosis; his plasma vWF-Ag level was $254.77 \mathrm{IU} / \mathrm{ml}$. C) IV cords large esophageal varices in 1.5-year-old male patient with extra-hepatic biliary atresia; his plasma vWF-Ag level was $579.77 \mathrm{IU} / \mathrm{ml}$

A

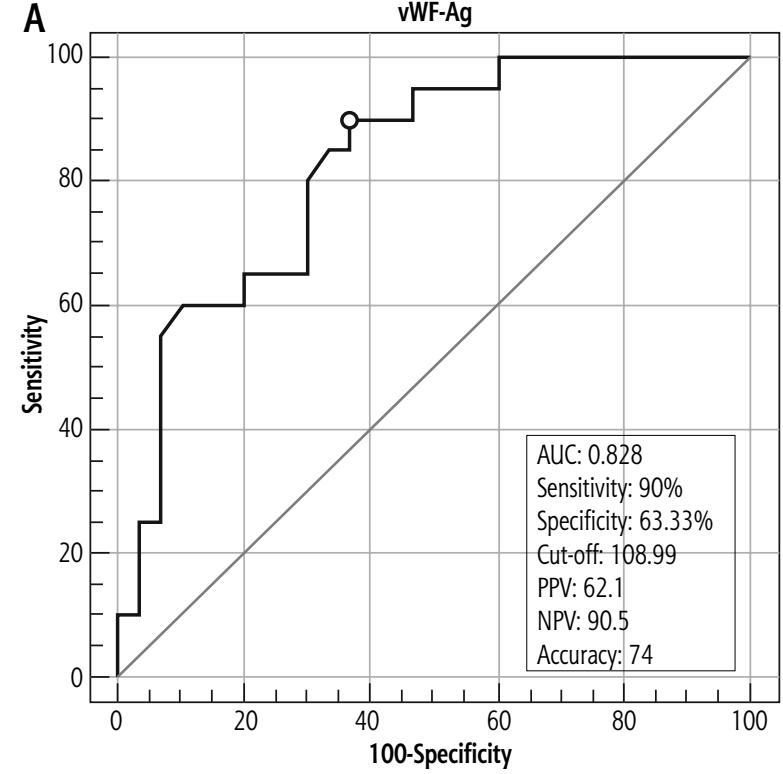

B

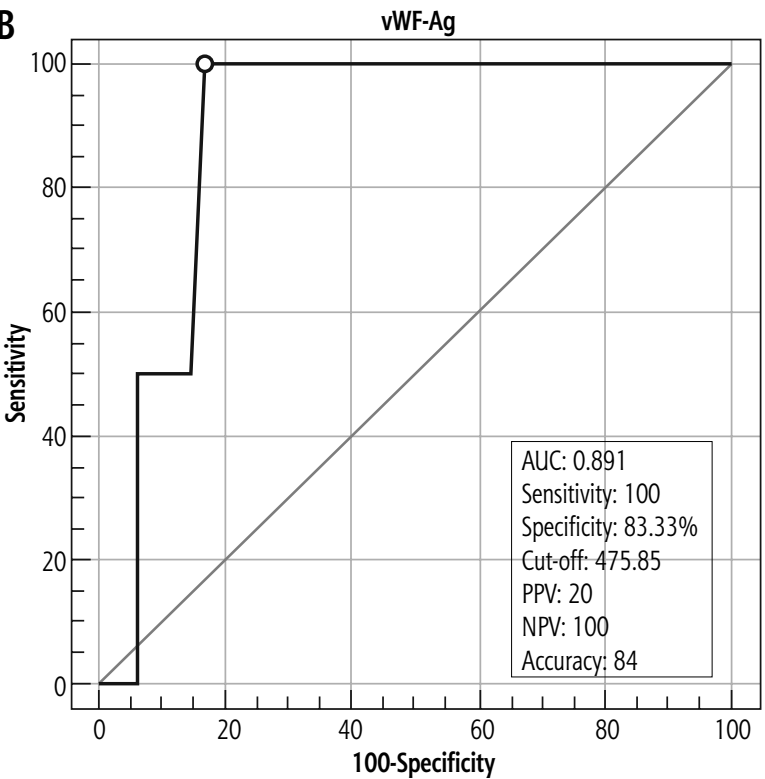

Fig. 3. A) Area under the ROC curve of plasma vWF-Ag level for discrimination of esophageal varices. B) Area under the ROC curve of plasma vWF-Ag level for discrimination of large esophageal varices

\section{Discussion}

In the current study, the majority of patients had undiagnosed CLD (26\%) and AIH (20\%), in general agreement with the study of Thajeel et al. [10], in which biliary atresia and undiagnosed CLD were the major etiologies among their study patients, while Pugliese et al. [11] reported biliary atresia, AIH and al-antitrypsin deficiency as major causes of CLD in their study.

We found that patients categorized as CPS-B formed the highest percentage (44\%), followed by CPS-A and CPS-C, in agreement with Thajeel et al. [10], who reported the highest percentage of their pediatric study group as CPS-B (49\%) in contrast to $32 \%$ and $19 \%$ as CPS-A and C, and in the study of Maher et al. [12] groups A, B and C comprised 26.7\%, $50 \%$ and $23.3 \%$, respectively.

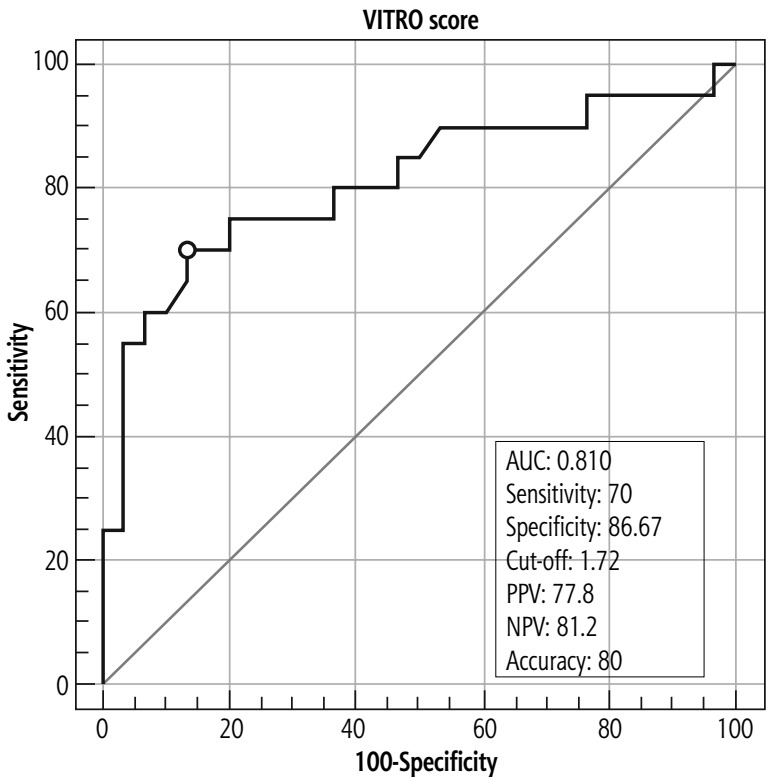

Fig. 4. Area under the ROC curve of VITRO score for discrimination of esophageal varices 
According to upper endoscopic findings, $40 \%$ of patients were classified as group I (patients had EVs) and $60 \%$ as group II (patients had no EVs), which was generally in agreement with Dell'Era et al. [13] and Hanquinet et al. [14], who documented that EVs were found in about $50 \%$ and $54 \%$ of their pediatric population. Also D’Amico et al. [15] and Garcia-Tsao et al. [16] reported similar results but in adult patients with CLD. On the other hand, some studies reported high prevalence rate of EVs in patients with CLD, such as Sezer et al. [17], who documented that EVs were found in $70 \%$ of their patients. Different age groups and degrees of compensation may explain the prevalence of variability.

Ghweil et al. [7] and Yilmaz et al. [18] reported that plasma vWF-Ag level increases in adult cirrhotic patients and this is accompanied by higher stages of cirrhosis according to CPS. Wu et al. [19] and Ferlitsch et al. [20] reported that $\mathrm{vWF}$ is a noninvasive predictor of $\mathrm{PH}$ and EVs in patients with cirrhosis, at cut-off values of $141 \mathrm{IU} / \mathrm{ml}$ and $241 \mathrm{IU} / \mathrm{ml}$, respectively, and increased levels of vWF in liver tissues may induce elevated plasma vWF levels, supporting our results which reported a high vWF-Ag level of $368.2( \pm 199.8) \mathrm{IU} / \mathrm{ml}$ in group $\mathrm{I}$ in comparison with its mean of 160.4 $( \pm 144.4) \mathrm{IU} / \mathrm{ml}$ in group II, with a highly statistically significant difference between the two groups $(p<0.0001)$ (Table 3 and Fig. 4 ), with a cut-off value of $108.99 \mathrm{IU} / \mathrm{ml}$ discriminating patients having EVs from patients without EVs (Fig. 3A).

In the present study, the vWF-Ag cut-off value of $475.85 \mathrm{IU} / \mathrm{ml}$ could discriminate patients with large varices from patients having small or medium sized varices, with $100 \%$ sensitivity and $83.33 \%$ specificity (Fig. 3B), in accordance with Mahmoud et al. [21], who found that plasma vWF-Ag was an independent predictor for detecting the presence of large EVs with good sensitivity (91.2\%) and specificity (85.7\%).

In the current study, we found that vWF-Ag level was lower in patients with blood group $\mathrm{O}, 121.37$ $( \pm 74.27) \mathrm{IU} / \mathrm{ml}$, than its mean in the non-O blood group, $282.09( \pm 207) \mathrm{IU} / \mathrm{ml}$, with a statistically significant difference $(p<0.05)$ (Table 4$)$, in agreement with Albánez et al. [22] who documented that vWF-Ag was significantly higher in non-O blood group individuals than in blood group $\mathrm{O}$ individuals $(p<0.0008)$.

On correlating vWF-Ag with different stages of hepatic fibrosis, it was found that vWF-Ag level had a positive correlation with degree of hepatic fibrosis, with a statistically significant difference $(p<0.05)$. Maieron et al. [23] also reported that vWF-Ag is one of the best markers to differentiate patients with fibrosis from patients without fibrosis.

Von Willebrand factor antigen is released by activated endothelial cells and therefore represents an indicator of endothelial cell activation and plays a crucial role in high shear stress depending on primary hemostasis. The endothelium plays a crucial role in many vascular diseases and endothelial dysfunction is a fundamental component of the increased hepatic vascular tone of cirrhotic livers. Activation of thrombocytes and endothelium finally leads to platelet aggregation and probably to microthrombotic events. Those events lead to increased portal pressure and furthermore might lead to worsening of fibrosis [20].

A positive correlation was found between vWF-Ag and total bilirubin, which is in harmony with the finding of Yilmaz et al. [18] who reported the same results among their cirrhotic patients and explain this by higher stages of cirrhosis (except cholestatic liver diseases) and increased bilirubin levels. High bilirubin levels accompany higher damage in liver and therefore this causes increased endothelial dysfunction. vWF-Ag level is a reliable marker of endothelial dysfunction and it was significantly high in cirrhotic patients with increased bilirubin levels in comparison to patients with normal bilirubin levels.

On the other hand, vWF-Ag level was negatively correlated with platelet count; these results were similar to data confirmed by Lisman et al. [24] who demonstrated that in cirrhosis elevated vWF plasma levels resulted in substantially elevated platelet deposition on collagen in a vWF-dependent, flow-driven, platelet adhesion assay. The increased adhesion induced by plasma and was independent of platelet count decrease, indicating that the increase in vWF might in part compensate for the quantitative platelet defects described in these patients.

Table 4. Comparison between group I and group II as regard blood-group

\begin{tabular}{lccc}
\hline Parameters & \multicolumn{2}{c}{ EV } & P-value \\
\cline { 2 - 3 } & Group I $(\boldsymbol{n}=20)$ & Group II $(\boldsymbol{n}=\mathbf{3 0})$ & \\
\hline Blood group 0 & $7(35 \%)$ & $5(16 \%)$ & 0.27 \\
\hline Blood group non-0 & $13(65 \%)$ & $25(84 \%)$ & \\
\hline
\end{tabular}


Also, plasma vWF-Ag level was negatively correlated with total protein and serum albumin level $(p<0.05)$, which is in harmony with the results of Yilmaz et al. [18], who found that vWF-Ag level was $177( \pm 61.2) \mathrm{IU} / \mathrm{ml}$ in patients with an albumin level of $>3.5 \mathrm{~g} / \mathrm{dl} ; 236.7 \pm 108 \mathrm{IU} / \mathrm{ml}$ for albumin levels between 2.8 and $3.5 \mathrm{~g} / \mathrm{dl}$ and $266.3 \pm 83.4 \mathrm{IU} / \mathrm{ml}$ for an albumin level under $2.8 \mathrm{~g} / \mathrm{dl}$, and all of the three groups had higher vWF levels in comparison to the control group $(p<0.001)$.

A negative correlation was also found between vWF-Ag and PV velocity, which was significant $(p<0.05)$, and low portal velocity had a statistically significant value in differentiating group I and group II as regards the presence of EVs, which strengthens our hypothesis of the value of vWF-Ag in predicting EVs.

On trying to discriminate patients having EVs from patients without EVs, depending on the VITRO score, we found that it was helpful with $70 \%$ sensitivity, $86.67 \%$ specificity and accuracy of $80 \%$ (Fig. 4). However, AST/ALT had no statistically significant difference $(p \geq 0.05)$, which was in agreement with Mattos et al. [25] who reported that AST/ALT ratio had no value in predicting EVs.

Also, APRI score was measured in both groups; it was found that there was no statistically significant difference between the two groups $(p \geq 0.05)$, which was in agreement with Stefanescu et al. [26]. On the other hand, Wang et al. [27] reported statistically significant value of the APRI score in predicting EVs. It could be attributed to their large sample size, more advanced stages of fibrosis and advanced degrees of decompensated cirrhosis among their patients.

No statistically significant difference was found on comparing the two groups in our study when platelet count/spleen diameter score was used to compare between the two groups. Chawla et al. [28] reported that platelets/splenic longitudinal diameter ratio of 909 may not be adequate to completely replace EGD as a noninvasive screening tool for EVs, which is against the findings of Gana et al. [29] and Adami et al. [30], who reported that the same parameter can predict the presence of EVs in children with cirrhosis and portal vein thrombosis at levels of 0.79 and 1.00 , respectively. Heterogeneity of patients studied and the etiological diversity of patients in our sample may explain the limited value of this parameter.

The limitation of this study is unavailability of healthy controls.

\section{Disclosure}

The authors declare no conflict of interest.

\section{References}

1. Rajoriya N, Gorard DA. Endoscopic management of oesophageal and gastric varices: endoscopy of GI tract. InTech 2013.

2. Tiwari D, Kumar S, Lahariya D, Jacob J. Comparison between platelet count, spleen diameter and their ratio with esophageal varices in patients with liver cirrhosis. Am J Med Sci 2016; 6: 29-33.

3. Biecker E. Portal hypertension and gastrointestinal bleeding: diagnosis, prevention and management. World J Gastroenterol 2013; 19: 5035-5050.

4. Ling SC, Walters T, McKiernan PJ, et al. Primary prophylaxis of variceal hemorrhage in children with portal hypertension: a framework for future research. J Pediatr Gastroenterol Nutr 2011; 52: 254-261.

5. Garcia-Tsao G, Friedman S, Iredale J, Pinzani M. Now there are many (stages) where before there was one: In search of a pathophysiological classification of cirrhosis. Hepatology 2010; 51: 1445-1449.

6. Franchini M, Lippi G. Acquired von Willebrand syndrome: an update. Am J Hematol 2007; 82: 368-375.

7. Ghweil AA, Arafa UA, Khodeary A, Salem AN. Predictors of bleeding from esophageal varices: the role of factor VII and von Willebrand factor (vWF). Open J Gastroenterol 2014; 4: 152.

8. Ishak K, Baptista A, Bianchi L, et al. Histological grading and staging of chronic hepatitis. J Hepatol 1995; 22: 696-699.

9. Park JM. Miscellaneous esophageal diseases. In: Clinical Gastrointestinal Endoscopy. Springer, Berlin, Heidelberg 2014; 87-98.

10. Thajeel RF, Al-Baldawi DH, Najim WA. Trace elements in children with chronic liver disease. J Clin Gastroenterol Hepatol 2017; 1: 20

11. Pugliese R, Fonseca EA, Porta G, et al. Ascites and serum sodium are markers of increased waiting list mortality in children with chronic liver failure. Hepatology 2014; 59: 1964-1971.

12. Maher M, Yosef TM, Sabry AI, et al. Hyponatremia and zinc deficiency as a risk factor for hepatic encephalopathy in cirrhotic patients. Life Science 2013; 10: 1493-1500.

13. Dell'Era A, Iannuzzi F, de Franchis R. Endoscopic Management of Variceal Haemorrhage. J Gastroenterol Hepatol Res 2015; 4: 1507-1514.

14. Hanquinet S, Morice C, Courvoisier DS, et al. Globus pallidus MR signal abnormalities in children with chronic liver disease and/or porto-systemic shunting. Eur Radiol 2017; 27: 40644071.

15. D'Amico G, Pasta L, Morabito A, et al. Competing risks and prognostic stages of cirrhosis: a 25-year inception cohort study of 494 patients. Aliment Pharmacol Ther 2014; 39: 1180-1193.

16. Garcia-Tsao G, Sanyal AJ, Grace ND, Carey W. Prevention and management of gastroesophageal varices and variceal hemorrhage in cirrhosis. Hepatology 2007; 46: 922-938.

17. Sezer OB, Çelik D, Tutar N, Özçay F. Can platelet count/spleen diameter ratio be used for cirrhotic children to predict esophageal varices? World J Hepatol 2016; 8: 1466-1470.

18. Yilmaz VT, Dincer D, Avci AB, Cetinkaya R. Significant association between serum levels of von Willebrand factor (vWF) antigen with stages of cirrhosis. Eurasian J Med 2015; 47: 21-25.

19. Wu H, Yan S, Wang G, et al. von Willebrand factor as a novel noninvasive predictor of portal hypertension and esophageal varices in hepatitis B patients with cirrhosis. Scand J Gastroenterol 2015; 50: 1160-1169.

20. Ferlitsch M, Reiberger T, Hoke M, et al. von Willebrand factor as new noninvasive predictor of portal hypertension, decompen- 
sation and mortality in patients with liver cirrhosis. Hepatology 2012; 56: 1439-1447.

21. Mahmoud HS, Ghweil AA, Bazeed SE, et al. Reliability of plasma von Willebrand factor antigen in prediction of esophageal varices in patients with liver cirrhosis. Open J Gastroenterol 2015; 5: 49.

22. Albánez S, Ogiwara K, Michels A, et al. Aging and ABO blood type influence von Willebrand factor and factor VIII levels through interrelated mechanisms. J Thromb Haemost 2016; 14: 953-963.

23. Maieron A, Salzl P, Peck-Radosavljevic M, et al. Von Willebrand Factor as a new marker for non invasive assessment of liver fibrosis and cirrhosis in patients with chronic hepatitis C. Aliment Pharmacol Ther 2014; 39: 331-338.

24. Lisman T, Bongers TN, Adelmeijer J, et al. Elevated levels of von Willebrand factor in cirrhosis support platelet adhesion despite reduced functional capacity. Hepatology 2006; 44: 53-56.

25. de Mattos AZ, Daros LF, de Mattos AA. Platelet count squared/ spleen diameter-aspartate aminotransferase ratio: non-invasive method to predict esophageal varices. Arq Gastroenterol 2017; 54: 222-224.

26. Stefanescu H, Grigorescu M, Lupsor M, et al. A new and simple algorithm for the noninvasive assessment of esophageal varices in cirrhotic patients using serum fibrosis markers and transient elastography. J Gastrointestin Liver Dis 2011; 20: 57-64.

27. Wang JH, Chuah SK, Lu SN, et al. Transient elastography and simple blood markers in the diagnosis of esophageal varices for compensated patients with hepatitis B virus-related cirrhosis. J Gastroenterol Hepatol 2012; 27: 1213-1218.

28. Chawla S, Katz A, Attar BM, et al. Platelet count/spleen diameter ratio to predict the presence of esophageal varices in patients with cirrhosis: a systematic review. Eur J Gastroenterol Hepatol 2012; 24: 431-436.

29. Gana JC, Turner D, Roberts EA, Ling SC. Derivation of a clinical prediction rule for the noninvasive diagnosis of varices in children. J Pediatric Gastroenterol Nutr 2011; 50: 188-193.

30. Adami MR, Ferreira CT, Kieling CO, et al. Noninvasive methods for prediction of esophageal varices in pediatric patients with portal hypertension. World J Gastroenterol 2013; 19: 2053 2059. 